Boise State University

ScholarWorks

World Languages Faculty Publications and

Presentations

Department of World Languages

$12-1-2012$

\title{
Individual Factors and Successful Learning in a Hybrid Course
}

Kelly Arispe

Boise State University

Robert J. Blake

University of California - Davis 


\title{
Individual Factors and Successful Learning in a Hybrid Course
}

\author{
Kelly Arispe \\ Boise State University \\ Robert J. Blake \\ University of California Davis
}

\begin{abstract}
What personality factors make for a successful hybrid L2 learning experience? While previous studies have examined online learning in comparative terms (i.e. Which format is better: in class or hybrid?), this study examines certain personality and cognitive factors that might define the ideal hybrid language learner. All informants studied introductory Spanish with multimedia materials supported by synchronous chat (video, voice, text). Personality and cognitive traits were probed using the Big Five Inventory scale (BFI1) and the Shipley Institute of Living scale (SILS2), respectively. The results were correlated with course outcomes and learner preferences for online, chat, or in-class activities. Exit interviews were conducted with an eye to offering a richer understanding of how hybrid students viewed online learning. The quantitative data revealed that conscientiousness (per BFI) had a significant, positive correlation with final grades. Low-verbal learners (per SILS) registered a definite preference for working with online materials, as opposed to learning in class or chatting online. The results suggest that students who are conscientiousness learners perform well within the hybrid learning environment; lowverbal learners, in particular, value the online materials which create the possibility to work online at one's own pace.
\end{abstract}

Keywords: successful hybrid language learning, Spanish, personality traits, Big Five Inventory Scale, conscientiousness, Shipley Institute of Living Scale, low-verbal learners, tri-modal chat, multimedia online activities.

\section{Introduction}

The integration of hybrid learning into the mainstream curriculum is beginning to gain a more prominent role in second language pedagogy and, consequently, researchers are becoming increasingly interested in measuring its role in L2 language development (Thorne, 2006). Some educators have characterized the hybrid format as representing the "best of both worlds" in the sense that it provides the learner with all the conveniences of online learning while still maintaining the face-to-face (F2F) link found in the classroom experience (Allen \& Seaman, 2010; Blake, 2008; Scida \& Saury, 2006; Young, 2002). According to Allen \& Seaman (2010) in the Sloan Consortium 2010 survey report, Class Differences: Online Education in the United States, there has been a twenty-one percent increase in online enrollment in just the last year, where thirty percent of all college students take at least one course online (p.2). Furthermore, 30 to $79 \%$ of the course content for higher education is delivered online in a hybrid format.

$1 \mathrm{BFI}$ is the Big Five Inventory Scale (John, Naumann \& Soto, 2008) that measures personality traits according to five main categories: extraversion, agreeableness, conscientiousness, openness and neuroticism.

2 SILS is the Shipley Institute of Living Scale (Senior, 2001; Zachary, 1991) that measures verbal and abstract intelligence. 
Allen and Seaman (2010) define as hybrid a course where a "substantial proportion of the content is delivered online, [a course that] typically uses online discussions, and [one that] typically has a reduced number of face-to-face meetings" (p. 4). Throughout this study we will use the hybrid to refer to courses that regularly combine scheduled classroom sessions with online meetings, although hybrid learning, also known as blended learning, varies considerably in definition and description (Graham, Allen \& Ure, D., 2005; Graham, 2006; Osguthorpe \& Graham, 2003; Reay, 2001; and Young, 2002).

In the present study we looked in depth at a hybrid course that was characterized by an online and face to face (F2F) learning environment where the participants attended two F2F class sessions per week, one weekly chat session using SCMC (Synchronous Computer Mediated Communication), along with a series of assignments completed online as part of a course multimedia, interactive online textbook. We were particularly interested in looking at individual differences--namely personality, verbal intelligence, and learner preferences--to determine if they have an impact on the outcome in a hybrid learning course. Little research has been carried out that might shed light on these individual learning differences in the hybrid learning environment. As hybrid courses grow in popularity, it is important to know which types of learners thrive in this type of language learning course.

\subsection{Literature Review}

From an intuitive standpoint, students who thrive in a hybrid online language course with tri-modal (i.e. video, sound, text) chatting appear to have strong individual study skills and an enjoyment for working independently (Irizarry, 2002). However, researchers have not yet teased out which personality traits and/or cognitive factors might help foster successful learning experiences within a hybrid-learning environment. Additionally, learner preferences have been largely ignored when it comes to understanding the role of CALL in language learning environments. For instance, "which learners prefer what?" If the prominence of online and hybrid courses is, indeed, on the rise, it would be both beneficial to language departments, as well as the instructors themselves, to know which aspects of the course are most beneficial from the student perspective. Although the second-language acquisition (SLA) field has acknowledged the importance of individual learning differences in general (Ehrman, 2008; Skehan, 1991; Wakamoto, 2009), few studies have focused specifically on their role in L2 language development in CALL learning environments. Most studies have examined student-learning styles using a field independent/dependent (FID) construct (Chapelle \& Jamieson, 2008; Chapelle \& Heift, 2009). The following section will outline some of the most important findings from these studies, while demonstrating the need for exploring further and understanding more fully learner differences and preferences in the hybrid-learning environment.

\subsubsection{Individual learner factors}

Skehan (1991) recognized that at the time he was writing, the field of Second Language Acquisition (SLA) was largely dominated by research that catered to language as a system (i.e. language transfer, fossilization, overgeneralization, etc.). For this reason, his article continues to serve as one of the pivotal pieces for highlighting what he believed was largely lacking in SLA: research that focused on the language learner as an individual. By highlighting previous studies on the patterns of language aptitude (Carroll, 1965) as well as the "casual influence" of Gardner's integrative and instrumental motivation dichotomy on language learning, Skehan made a strong argument for future research that looked more in depth at the qualities that make language learners successful or unsuccessful. Furthermore, he underscored the challenges encountered in understanding both the role of learning strategies and learner styles. Figure 1 below summarizes the key areas that he addressed.

\section{(INSERT Figure 1)}

Although Skehan clearly outlines the importance of these individual differences (ID) as a way of reaching a better understanding of the language learner, research on IDs is still largely underrepresented in the field of SLA. For example, even though the role of personality has been highly relevant for the educational psychology literature (Ackerman \& Heggestad, 1997; Busato, Prins \& Elshout, Hamaker, 1999), very few L2 studies have researched the role of personality. Nevertheless, Ehrman (2008) demonstrated that the differences in personality correlate with measures of language proficiency. 
Ehrman conducted a study on personality and what makes the best language learner according to standards based on the five-point scale for oral interviews developed by the Interagency Language Roundtable Scale (ILR). She selected adult second language learners that achieved level-four proficiency (near-native proficiency) and looked for similarities in their personalities according to the Myers-Briggs Type Indicator personality test (Myers, McCaulley, Quenk and Hammer, 1998). She found that the factor known as intuition stood out among the best language learners. She suggested that intuitives "concentrate on meaning, possibilities, and usually accept constant change. Intuitives tend to be oriented toward the future-what might be or what probably will be" (p.66). Furthermore, she mentions that intuition often correlates with openness on the Big Five Inventory personality scale. Surprisingly, she also found that intuition was most represented among the high-achieving language learners along with the trait of introversion. Although these findings appear to contradict most of the research that has concluded that extroverts are better language learners (Dewaele and Fyrnham, 1999), Ehrman suggested that introversion, in this case paired with intuition, enabled learners to have a heightened "sensitivity to archetypal, universal patterns" in language learning. Finally, she concludes that teachers need to create a space in classroom teaching where learners are not forced to participate in activities that solely cater to extravert personalities, but instead provide a variety of activities that encourage learners to use their intuition and analytical skills while making sense of the second language (p.69).

In a similar manner, Wakamoto (2009) has looked carefully at the role of learner strategies and two personality traits, extroversion and introversion, as indicators of proficiency in listening comprehension for Japanese learners of English, as measured by several surveys and a proficiency test (Myers-Briggs Type Indicator, MBTI; Strategy Inventory for Language Learning, SILL; and the Comprehensive English Language Test, CELT). Although Wakamoto focused solely on extroversion and introversion, she acknowledges that these two constructs are based on the personality taxonomy outlined by the BFI scale (p.

19). In line with Skehan (1991), Wakamoto's study was a direct response to the fact that personality factors have persistently gone unexamined in SLA literature. "In SLA research, however, extroversion has been the 'unloved' variable (Deweale/Furnham 1999) and personality variables have tended to be omitted from the second language (L2) research agenda" (Griffiths 1991). Wakamoto found that the differences in personality correlated strongly with different learner strategies, although her conclusions about personality factors as a measure for success were ultimately inconclusive. Nevertheless, she argued that examining personality factors may tell us a more complete developmental story than only looking at proficiency measures because of the potential interactions with learner strategies (p.120).

\subsubsection{Learner differences and CALL}

Chapelle \& Heift (2009) have recently conducted research that highlights individual learner differences within the field of CALL. Specifically, they look at the individual learning style of Field Independence/Dependence (FID) and argue that these individual differences are not simply "traits" but should be understood within an interactionist construct that takes into consideration the individual and his/her interaction within the CALL context. In short, field independent (FI) learners prefer to work on their own (without collaborating with others) and generally perform better in the classroom. On the other hand, field dependent (FD) learners enjoy collaborating with others and value guidance. Furthermore, they more positively view the CALL environment than FI learners (Chapelle \& Jamieson, 1986).

Their study looks at a 30-item questionnaire that was completed by 50 university students enrolled in a first year German course. Students enrolled in this course were given access to E-Tutor (Heift, 2001; Heift \& Nicholson, 2001) and the main research questions were aimed at evaluating whether or not the FID-CALL scale was a reliable measure for the FID construct as well as to corroborate previous findings that FD learners have a more felicitous experience using the CALL tool.

Their initial findings were ultimately inconclusive because they found that the FID-CALL scale was not a reliable measure for determining significant differences between learners. However, they were able to look in-depth at five questions from the survey that were predictive in distinguishing between FID learner differences. Their analysis shows that FD learners preferred help and this finding supported the results from 
NOTICE: this is the author's version of a work that was accepted for publication in System. Changes resulting from the publishing process, such as peer review, editing, corrections, structural formatting, and other quality control mechanisms may not be reflected in this document. Changes may have been made to this work since it was submitted for publication. A definitive version was subsequently published in System, 40(4), 2012.

DOI: $10.1016 /$ j.system.2012.10.013

previous studies (Chapelle \& Jamieson, 1986). Chapelle \& Heift ultimately concluded that more research needed to be conducted with a more reliable FID-CALL survey.

\subsubsection{The BFI and SILS scales}

The Shipley Institute of Living Scale (SILS; Senior, 2001; Zachary, 1991) was originally developed in 1940 by Walter Shipley as a way to assess "general intellectual functioning in adults and adolescents"(Senior, 2001). The Big-Five Inventory Scale (BFI; Naumann, \& Soto, 2008) is a broad measure of personality traits that seeks to enable researchers to reach conclusions about the individual differences in behavior and experience for each participant based on five main categories: extraversion, agreeableness, conscientiousness, openness and neuroticism. These scales have been widely used for studies in the psychology field, although not without criticism (Paunonen, 2001), but rarely employed by applied linguists doing L2 studies. From a methodological standpoint, our findings do not imply that the BFI and SILS scales are the only instruments--or even the best ones--for defining the personality and cognitive profile of online learners. Rather, these measures have been used extensively (Bowers, 1998; De Raad, 2002; Hurtz, 2000; Zachary, 1985 \& 1991) because they represent well-established tools in the social sciences with a long track record of reliable use and, as such, offer promise for advancing the present line of research.

\subsection{Research questions}

The intent of this study, then, was to explore the social and/or cognitive qualities that might characterize a successful hybrid learner. As discussed above, very few studies have looked at the importance of individual differences, and within the field of CALL previous research has focused solely on the FID construct. For this reason, we looked at four constructs within Skehan's model (1991) with the goal of narrowing the gap between the field of CALL research and that of individual learner differences.

Specifically, we set out to examine how the BFI personality traits and Shipley cognitive factors (see section 2.3 for a detailed description of the testing instruments) aligned with final grades and learner preferences respectively for classroom instruction, online chatting, or the use of online materials. We sought to answer questions such as which course components did extroverted or introverted learners with strong or weak verbal skills judge to be most valuable. We were interested in understanding and portraying the learner perspective with respect to hybrid learning environments by highlighting students' individual needs, desires, and experiences. With these goals in mind, we gathered both quantitative and qualitative data in order to create a profile of the ideal hybrid online language learner. The following research questions guided the design of the study:

1. Which personality traits (e.g. extraversion, agreeableness, conscientiousness, neuroticism, openness) are associated with success in hybrid online language learning and learner preferences?

2. Which cognitive factors (e.g. verbal and abstract skills) affect learning outcomes (i.e. grades) and preferences?

3. How do the hybrid learners themselves view their respective experiences with an online course?

Our overall goal was to initiate a line of research whose purpose is to ascertain which types of students are likely to have positive experiences learning language in a hybrid learning environment as a function of certain personality and cognitive traits. We hypothesized that learners that succeed in the hybrid course (as measured by final grade) would be conscientious, open, and extroverted, as well as possess high verbal skills. Furthermore, we hypothesized that high verbal and low verbal learners would demonstrate a preference for online chatting, and low verbal learners would also prefer the online course materials. This study was intended to spur additional research focusing on individual differences, a consideration that will become increasingly important as online course offerings continue to expand in the future. 


\section{Materials and Methods}

\subsection{Population and Sample}

Sixty-four subjects from a research university in California participated in our study over three years3. Fifty-one of the participants were enrolled in a hybrid course that was designed for students at a secondquarter Spanish level who have some basic familiarity with Spanish (i.e. novice, low-mid). Thirteen of these participants were enrolled in the third quarter level, which corresponds to third quarter Spanish4. For the majority of the participants $(70 \%)$, this was their first exposure to any type of online course, hybrid or completely virtual.

\subsection{Nature of the hybrid course Tesoros}

These first-year Spanish hybrid courses consist of the three following components: (1) Tesoros online multimedia materials (Blake \& Blasco, 2001), previously published in a DVD format, but now delivered within a MOODLE wrapper with SCORM-compliant activities5; (2) Wimba classroom, a tri-modal Flashbased SCMC tool that accompanies the Tesoros Moodle course; and (3) class meetings two days a week for fifty minutes. On average, students spent two hours per week in class, one half to one hour chatting trimodally, and seven hours working independently on the Tesoros web site.

The role of the instructor was to scaffold the learner through carefully planned classroom meetings designed to support the online course website. In addition, the instructor served as a mediator during the trimodal chats where students met online once a week in groups of two or three. Online chat sessions encouraged students to negotiate meaning through task-based activities (see Appendix B). They lasted thirty minutes and typically modeled the following format: 1) warm-up/greeting, 2) 1-2 information gap activities pertinent to the vocabulary and grammar sections in the chapter, and 3) a cool-down/goodbye.

\subsection{Data collection and testing instruments}

Each subject gave his/her consent to participate in the study according to standard Institutional Review Board (IRB) ethical stipulations. All participants were given two tests and a survey administered in class toward the end of the quarter. The instruments probed four components: 1) the BFI personality test, 2) the SILS cognition test, 3) a survey of self-reported learner preferences, and 4) a series of open-ended questions designed to provide a qualitative understanding for the student's experience in the hybrid course. In addition, classroom and chat observations were conducted to get an overall feel for how participants interacted both individually and in groups and to see if their behavior differed in the F2F context as opposed to online learning environments.

First, we examined the role of personality and intelligence. We relied on the educational psychology field for reliable measures of personality traits and verbal intelligence with an eye to correlating these independent variables with overall online learning success. As is evident from Skehan's model and other studies (Bacon, Handley, Dennis \& Newstead, 2008; Chan, Cheung, Sze, Leung \& Cheung, 2008), intelligence as measured by I.Q. seems to play a part in determining learning performance. More specifically, vocabulary tests that measure verbal intelligence were often used to gage intellectual functioning and second language aptitude (Chan, Cheung, Sze, Leung \& Cheung, 2008, p.892; Sasaki, 1996; Skehan, 1989; also see Wechsler, 1997, 2003 \& Roid, 2003).

Accordingly, we correlated results from the BFI and SILS with hybrid course final grades, a standard institutional measure of successful academic progress; correlations with grades are a fairly common practice in the education literature (U.S. Department of Education, 2009). Although final grades might not

3 Over the period of three years, there were three different instructors for the 64 participants. The same syllabus was administered and the classroom procedure was fairly standardized.

4 Most, if not all participants had taken elementary Spanish in high school one to three years previously. The SPA 2V-3V series was specifically designed for these false beginners.

5 SCORM is an automatically graded protocol written in Java script that keeps track of student progress. 
constitute an ideal measure of linguistic proficiency (in the sense that an OPI assessment claims to be), grades directly reflect student effort and global development as well as providing an indication of whether or not the students underwent a felicitous learning experience, in this case, via an online format. A good grade in any course will, understandably, motivate students to repeat the experience and continue to develop their knowledge of a given subject matter. By contrast, a low grade in an online course should alert us to the fact that minimal L2 learning occurred, which could possibly deter a student from pursuing further L2 studies. With respect to this study, we have interpreted high final grades as a sign of meaningful L2 development (although different from more formal definitions of linguistic proficiency) and low final grades as the opposite, a show of minimal L2 incremental progress. Good grades, of course, entail no predictions concerning a student's overall or future L2 linguistic competence or achievement--nor was that the concern of the present study. In the present study, then, grades should be seen as a global indicator of achievement and student satisfaction that can help guide the profession as it grapples with the task of designing optimum online learning environments. We have already discussed elsewhere (Blake et al., 2008), the issue of whether or not gains in proficiency using online formats are comparable to the student outcomes produced in traditional classroom formats and, likewise, this topic does not constitute the focus of the present study.

Among the different measures used to determine personality traits, the BFI is a respected and popular instrument used in the field of psychology (John \& Srivastra, 1999). Accordingly, we correlated the BFI results with the final grades, using the latter as a rough measure of a successful outcome in a hybridlearning environment. A brief description of the qualities associated with the five dimensions of the BFI is listed below:

\section{[Insert figure 2]}

In addition to individual BFI social factors, we also felt it was important to establish which cognitive factors play a role in hybrid learning success. For this reason, we employed the SILS measure as the appropriate estimate for the level of verbal and abstract intelligence of each participant. SILS, a test administered in English, consists of two main subsets: vocabulary and abstraction. In the vocabulary portion of the test, the subject had to choose the closest meaning between the target word and one of the four other words in the sequence. The test relies on verbal skills in the subject's native language of English and probes reading ability, verbal comprehension, acquired knowledge, long-term memory, and concept information. The reason we administered this test in English is to gain an accurate portrait of their cognitive abilities. Doing so in the L2 would understandably mask true cognitive capabilities. It should also be noted that all participants were native English speakers. The abstraction subset consisted of sequences of numbers, letters or words that were missing a final element that the participant had to complete. The abstraction portion of the test relies on attentional abilities, letter, word, and number concept formation, abstract thinking, cognitive flexibility, analysis and synthesis, processing speed, long-term memory, and specific vocabulary and arithmetic skills. Given the recognized validity and reliability of the SILS scale (Senior, G., 2001; Zachary, 1985 \& 1991), it seemed appropriate as a measure of the cognitive abilities for each participant in the present study.

The third component of the quantitative data collection was based on the self-reported responses concerning each participant's learner preferences. The participant had to rate his/her preference $(1=$ least helpful, $2=$ helpful, $3=$ most helpful) concerning the three course components: class meetings, weekly online chat sessions, or independent work with the online course website. In other words, participants were asked to rate the component that was most helpful in his/her success as a student.

Finally, each participant was asked to respond to a series of open-ended questions once they completed the BFI and SILS tests (please see Appendix A). Based on these responses, the researchers selected and interviewed three participants that performed along a continuum of low-performance to high-performance in the course, as well as along a continuum of satisfaction for the hybrid-learning environment in general. These participants' reflections will be discussed along with the quantitative data in order to give a more complete characterization of the hybrid language-learning environment. 


\section{Results}

\subsection{Data Analysis}

Responses to the BFI, SILS, and learner preferences survey were coded and analyzed to determine which factors might be associated with success in the class as measured by final grades, midterm grades, final exam grades as well as final oral exam grades. Pearson correlations, as well as Spearman's Rho and Kendall Taub correlations were used because they are particularly beneficial for interpreting ordinal data. For this study, the only dependent variable that correlated with the independent factors was final grade. For this reason, midterm, final exam and final oral exam grades were excluded from the tables 1,2, and 3 below.

Careful attention was also given to the correlations between the BFI and final grade and SILS scores and student preferences because we were interested in tracking how personality traits interact with course outcomes and SILS scores aligned with learner preferences (i.e. online textbook, online chat, or traditional class sessions), following an approach similar to Wakamoto's work (2009). Scores from these standard instruments were correlated with the final course grades in percentage for 64 students enrolled in the second and third quarter hybrid beginning Spanish language courses.

In the next section, we present and discuss the results of the study in the following order. First, we look at all 64 participants in relation to their personality traits as correlated with their respective final grades. Second, we examine verbal and abstract intelligence (cognitive factors) as correlated with learning preferences (online textbook, chat, or class). Third, we will discuss responses based on the interviews conducted with three participants in the second and third quarter Spanish hybrid courses who are representative of low, average, and excellent student outcomes.

\subsection{Quantitative results}

\subsubsection{Personality traits and learner preferences}

Conscientiousness is the only BFI trait that showed a highly significant correlation with final grades $(r=$ $.38), p=.002$ level . Furthermore, openness correlated significantly with student preferences for the F2F setting (class meetings) $(p=.045)$. There were no significant correlations between personality factors and student preferences, nor final grade and SILS scores and therefore these are not represented in the tables or discussion.

\section{[Insert table 1]}

This finding does not appear to be surprising because from the outset we had hypothesized that learners enrolled in any type of online course--whether hybrid or fully online--would need to demonstrate the ability to work independently in order to develop their L2 competence. Nevertheless, the construct of conscientiousness is subtly different from those of FI and FD discussed above (Chapelle \& Heift, 2009). Conscientiousness is a trait that both students who prefer to work alone and those who thrive in collaborating with others could possess. In other words, students who work methodically (i.e. they have the BFI trait of conscientiousness) perform well in a hybrid environment.

Perhaps the BFI construct of openness comes closer to the notion of FD learners who enjoy collaborations, but openness did not correlate with grades in our study, in contrast to Chapelle \& Heift's (2009) findings. However, openness correlated significantly with student preferences for the F2F setting. There was no significant correlation for openness and online chat or the online materials. This finding may have something to do with the issue of anonymity (i.e. there is less anonymity in class meetings which requires a greater level of openness), although more research is needed to make any further observations. 


\subsubsection{Cognitive factors and learner preferences}

We also looked at the correlations between all the independent variables. The relationship between learner preferences and verbal intelligence proved most intriguing. As shown in table 2, there is a statistically significant negative correlation $(\mathrm{r}=-.316)$ at the $\mathrm{p}<.012$ level for verbal intelligence and a preference for the online textbook. In other words, learners who have low verbal abilities prefer the online textbook. The Shipley score (verbal intelligence + abstract intelligence) also negatively obtained for a preference for the online textbook $(\mathrm{r}=-.321$ at the $\mathrm{p}<.010$ level); Clearly, high-verbal learners did not like using the online textbook, whether this was due to their more critical view of its context and/or style or because this learning aid was irrelevant to their strong and steady linguistic progress. Low-verbal learners preferred the online textbook over other course components. This finding underscores the importance of an online asynchronous component in online course design.

[Insert table 2]

\subsection{Qualitative results: Follow-up Interviews}

In order to gain a broader understanding for what these quantitative results might mean, we conducted three exit interviews in order to gather a qualitative assessment for three students who performed along a continuum of low-performance to high-performance in the course. Again, we were interested in the learner's perspective and how L2 learners evaluated the overall experience found in a hybrid-learning environment. Table 3 reveals how each student performed overall in the course, final grade, on the BFI personality scale, and on the SILS intelligence tests. We expected that the interviews would reveal information about learner preferences in an online learning environment that could not be captured by the BFI, SILS, or survey results. For instance, even through the chat component failed to correlate significantly with any of this study's variables, we still wished to know whether the students valued carrying out online synchronous exchanges. Did they value online chat as a way to become more successful in the course? Likewise, we wondered how students would define the advantages of online learning in their own words?

[Insert table 3]

\section{Participant A}

While Participant A, a low performer, stated that he enjoyed chatting online, other factors like verbal intelligence, overall conscientiousness and self-motivation (as determined from his open-ended responses) weighed heavily against his success in terms of the final grade. Despite his poor course performance, he repeatedly acknowledged how much more comfortable he felt speaking in Spanish online as compared to in class because he felt relaxed and free to experiment (i.e. make mistakes).

Anytime you're not in the same room with somebody and you don't get to see their face, you 're free to just make mistakes. You're free to be who you are. But any time you see somebody make facial expressions- their eyes and you're watching their body language, so it's different. So it was real relaxed talking...it was better for me to speak. Because sometimes when you're in somebody's presence there is kind of the expectation for you to get a certain word right but if they're not in your presence it's like okay this is how you say it okay cool and then you're cool.

Clearly, chatting online lowered Participant A's affective filter and allowed him to feel more successful and at ease with his overall production. Indeed, Smith, Alvarez-Torres and Zhao (2003) have noticed this phenomenon of "anonymity" as one of the four main descriptors in their taxonomy for classifying the affordance of CMC technologies. "In the vast anonymity of cyberspace there is little pressure of the sort imposed on an individual by another's physical presence. This is significant in terms of current second language theory, which views affective factors as key to the learning process" (707). Even though, in this 
NOTICE: this is the author's version of a work that was accepted for publication in System. Changes resulting from the publishing process, such as peer review, editing, corrections, structural formatting, and other quality control mechanisms may not be reflected in this document. Changes may have been made to this work since it was submitted for publication. A definitive version was subsequently published in System, 40(4), 2012.

DOI: $10.1016 /$ j.system.2012.10.013

course, each participant engaged in tri-modal chat whereby they were able to see one another via video, which differs in the degree of anonymity that is provided when left to text chat alone, participant A feels "less pressure" while chatting online, even with a video camera. In fact, participant A felt that his Spanish oral production improved when he was chatting online:

I think I was surprised how quickly I was formulating sentences. Cuz I don 't know I was just being me but if I was in front of a group of people it would be like "oh what's that word, uhhh" but if it's just me I'd just run with it and speak and it's cool and it's fun like that. And I surprised myself so it builds confidence when you 're chatting.

Despite his appreciation for tri-modal chat, participant A was still one of the lowest performers in class as measured by the final grade (0.67). Thus, the other components of the class (classroom and online learning) were more significant in determining his overall performance. In addition, his verbal skills were very low $(60 \%)$ and his overall SILS score was likewise low (70\%).

Furthermore, it's interesting to note that this student had the lowest BFI score for conscientiousness compared to the other participants. Participant A had a hard time turning assignments in on a timely manner and commented on the fact that he would frequently complete his online assignments for the week just hours before they were due. Thus, in spite of his overall satisfaction with chatting online, participant A did not feel that the hybrid-learning environment was the best fit for him and he did not continue with the second part of the series. The following response explains why he chose to drop the hybrid series:

I need constant teacher interaction. If it's on your own...it's cool because you don't have to go to class everyday but Spanish is one of those type of things you have to do all the time because you're around English everyday. If you just have a little bit of Spanish, you're not gonna really get it that much so to have a teacher that's there to open our books so I can see stuff and go back and flip and I just need that interaction with the teacher, it's more structured when you have a teacher. He or she is delegating stuff. Online it's kind of standard.

Given this participant's lack of self-motivation, we can begin to understand his preference for the classroom teaching with the assistance of an instructor and constant reinforcements as opposed to the environment afforded by an independent learning track. Although he was very successful in the chat component of the course, his low motivation, low conscientiousness, and preference for classroom learning--coupled with his low verbal scores--all contributed to his poor performance in the course.

\section{Participant B}

Participant B, a good learner with an average final grade (.80), was a successful student that received high scores in the class and on the SILS. Interestingly enough, despite his relative silence in class, his performance on the chat assignments was outstanding. In class he never made eye contact with the professor or with the other students and never voluntarily participated. When students were asked to work on an activity in groups in class, he eschewed working in groups and demonstrated a certain level of insecurity about his ability to speak in Spanish in class.

Yet, when he met online during his chat session, he was one of the best performers in tri-modal chat. He showed enthusiasm, motivation and sincere interest and was an active participant in completing task-based chat assignments online with group members. Towards the end of the quarter, he even began to joke with his group members in the target language. Since students in the class would chat with the same group once a week for the entire quarter, one could say that they formed a sense of community. For participant B, this mini-community was a place where he was transformed into an active, participatory, and motivated learner. When asked to reflect upon his online chatting experience, he said that he enjoyed chatting online in groups 
and even considered himself a "group person", the exact opposite of the instructor's informal in-class observations of him.

Yeah, I'm a group person. I think it takes less pressure off of you...we could all relate to the same thing because we're kind of beginners in Spanish. And we talk to each other and we kind of help each other out.

Clearly, he appreciated the community feel that he found in the group that he met online with week to week (also see Lord \& Lomicka, 2008 and Müller-Hartmann, 2005).

Lastly, what is also interesting about participant B is his strong preference for the in-class sessions. $\mathrm{He}$ rated the class sessions as the most helpful component in the class above the online chat and online course web site. When asked to elaborate, he says:

I would still think the teaching comes first because you're getting someone in the classroomsomeone who knows Spanish and I think the textbook is the least helpful. I don't know, the chat or the textbook. I think the teacher comes first because I'm used to classes, this is my first online class.

It would appear that part of the reason participant B feels this way is simply due to the fact that this is a new experience for him and one to which he is not fully accustomed. On the other hand, it might also be the case that he was a successful independent learner who does well in a hybrid-learning environment where he still can enjoy the benefit of the traditional classroom setting twice a week. His satisfaction with the course was such that he eagerly took the hybrid third quarter course the following quarter. In other words, participant B seems to fit the mold for the prototypical good candidate for the hybrid-learning environment.

\section{Participant C}

Participant $\mathrm{C}$ was one of the highest performers in the hybrid course as judged by the final grade (.91); this was also his first experience taking a class online. In fact, his verbal and overall Shipley scores were some of the highest values registered of all 64 participants. As is evident from his final grade and test scores, participant $\mathrm{C}$ was a very successful hybrid learner. He rated the online textbook as the most valuable component of the class followed by chat sessions in direct contrast to his disinterest in class sessions.

Participant $\mathrm{C}$ was very pleased with the second quarter hybrid course and continued on with the third quarter hybrid course the following quarter. In the interview he even expressed his desire that the hybrid course was offered at the intermediate and advanced levels. His satisfaction with the course was also due to the fact that he was given the freedom to learn language in an independent manner, where CALL enabled him to experiment and interact in the target language at his own pace, while still receiving the benefit of teacher feedback and scaffolding. He appreciated the convenience of the course and the fact that he was not restricted to go at the same pace as everyone else.

It's so much easier doing it twice a week and doing the rest on your own. For me, it's like when

I'm at home I can work at my own pace rather than at other people 's pace.

For this participant, the hybrid-learning environment was just the right fit.

\section{Discussion}

There is little doubt that students will increasingly be directed or have the option to enroll in hybrid courses as the popularity of this format continues to grow in higher education among administrators and teachers alike. In this study, we examined the question of whether or not all language students are equally ready to 
take advantage of this new online learning environment. In order to make informed curricular plans, language departments need to have a clear understanding of which types of students are likely to have a positive online language learning experience. Students, for their part, need to know what will be expected of them in these new learning environments. While understanding language proficiency gains in hybridlearning formats constitutes a legitimate area of research, we set out to track what social and cognitive factors might have conditioned a successful L2 experience, a notion often summed up, at least from the students' point of view, by their final grade.

Our research has provided some evidence that conscientious learners, as measured by the BFI scale, tend to thrive in hybrid language courses. These types of learners make goals and have a clear plan for their learning process. In a word, they are self-motivated and less subject to or dependent on the type of constant teacher reinforcement that is uniquely available in a supportive, F2F classroom. This is not to say that successful in-class learners are not conscientious, but rather that conscientiousness was significantly correlated as the principal BFI indicator of success in online learning environments. In SLA and CALL circles, the construct of learner autonomy has become increasingly attractive (Murphy, 2008; Schwienhorst, 2008). Its basic tenets, however, have been in play for some time as can be seen by Sinclair's (1999, p. 310) comments below:

The establishment of self-access and learner resources centers, the increase in distance learning programs, and a greater involvement of IT in language tracking all demonstrate this professional concern with empowering learners to be more effective and more independent in their language learning. (310)

The first finding suggests that online learning may not be an ideal format for every type of language learner, and that students should be informed before enrolling in this format that a high degree of conscientiousness is required in order to do well.

The second finding of this study correlates low verbal learners' preferences with online materials such as Tesoros. This leads us to hypothesize that low verbal students might benefit proportionally more than high verbal students from self-paced self-study components of an online course (also see Heift, 2010). Further research is needed here to explore these issues more thoroughly.

Further research should also seek to determine whether or not these preferences expressed by low-verbal learners might have something to do with the rapid pace and verbal delivery common to F2F interactions and the modern communicative classroom. Low-verbal learners during the first year of L2 language study might simply be overwhelmed by fast-talking native or near-native instructors who are trying to model reallife speech. Further studies might also look to correlate these trends with proficiency levels. These lowverbal students appear to require more time for individual language study and practice where they can fully control the pace of their learning. The interview responses from participant A might suggest this interpretation is worthy of closer attention by the field.

Although there were no statistically significant correlations between online chatting and final grade, strong preferences for synchronous chatting emerged in the qualitative, open-ended survey responses among highverbal and low-verbal participants. Furthermore, the ideas expressed in the three exit interviews demonstrated a pronounced enjoyment for speaking Spanish without the pressures normally encountered in F2F contexts (i.e. "the freedom to make mistakes" and "do relaxed talking"). The opinions revealed in these interviews help complement the quantitative results and give a more complete picture of the affordances found in online language learning.

\section{Conclusion}

Overall, our findings seem to suggest that hybrid language courses are a responsible option for the foreign language curriculum, especially for those students who are strongly self-motivated or have cultivated the personality trait of conscientiousness. Hybrid courses with an online component that empowers individual language study and practice through online materials are particularly attractive because even the low-verbal learners seem to be advantaged. In addition, we uncovered a small measure of subjective evidence through 
the exit interviews that speak to the importance of including a synchronous chat component, although this course component was not statistically correlated with the BFI and SILS factors examined in this study.

Whether or not hybrid courses represent the "best of both worlds," as Allen and Seaman (2010) have suggested, is not really a necessary claim. Hybrid language courses are a good fit for conscientious, highverbal, and even low-verbal learners--and that covers a significant proportion of our student population. Now, the language profession much endeavor to create and implement online materials that adequately provide tutorial CALL--individual language study and practice--at least in the early stages of learning, which was the context of this study.

On a more cautionary note, this study has little to say about what contribution CALL can make toward the attainment of advanced proficiency, a level where subtle but crucial pragmatic and cultural knowledge comes into play. What affordances, if any, can CALL offer in lieu of having access to the benefits offered by study abroad (Davidson, 2007) needs to be addressed by future studies. The processes involved in learning online are just beginning to be examined with a focus other than the proverbial comparative question, "which is better?"

Likewise, this study says little about the gains in proficiency attributable to the online format; the final grade, a fairly insensitive measurement of competence, was the only measure correlated with the social and cognitive factors. In future language studies, researchers will have to determine if more sensitive and revealing measures of course success are available or are in need of being developed. In addition, some of these personality traits and preferences identified in this study are not necessarily set in stone and might be subject to experimental treatments or explicit priming--additional topics that remain unexplored in the CALL literature but need to be investigated with an eye to shaping future online course design. Researchers need to explore whether or not certain online interface features might stimulate conscientiousness for all online language users.

Finally, future studies should look in depth at the role of learner autonomy (Little, 2004; Murphy, 2008; Schwienhorst, 2008) as a possible characteristic that determines hybrid-learning success and find the proper instruments to measure this construct. In many cases, such as in this study, hybrid language learning courses are often limited to the first year of study and longitudinal data is limited, if not extremely difficult, to collect. As hybrid offerings expand, it is imperative that researchers evaluate language development in this hybrid environment over longer periods of time in order to look critically at the issues of learner autonomy. 

made to this work since it was submitted for publication. A definitive version was subsequently published in System, 40(4), 2012.

\section{References}

Ackerman, P.L., Heggestad, E.D, 1997. Intelligence, personality, and interests: Evidence for overlapping traits. Psychological Bulletin. 121, 219-245.

Allen, E., Seaman, J, 2010. Class differences: Online education in the United States. retrieved August 2 , 2011 at http://www.sloan-c.org/. Babson Survey Research Group.

Bacon, A. M., Handley, S. J., Dennis, I., Newstead, S. E, November 07, 2008. Reasoning strategies: The role of working memory and verbal-spatial ability. European Journal of Cognitive Psychology. 20, 6, 1065-1086.

Blake, R. J, 2008. Brave new Digital Classrooms: Technology and Foreign-Language Learning. Georgetown, Washington, D.C.: Georgetown University Press.

Blake, R., Blasco, J., 2001. Tesoros: A multimedia-based course. New York: Mc-Graw-Hill, Inc.

Blake, R., Wilson, N., Pardo Ballester, C. \& Cetto, M., 2008. Measuring oral proficiency in distance, faceto-face, and blended classrooms. Language Learning and Technology. 12, 114-127.

Bowers, T. \& Pantle, M. 1998. Shipley Institute for Living Scale and the Kaufman Brief Intelligence Test as Screening Instruments for Intelligence. Assessment. 5:2, 187-195.

Busato, V. V., Prins, F. J., Elshout, J. J., Hamaker, C, 1999. Intellectual ability, learning style, personality, achievement motivation and academic success of psychology students in higher education. Personality and Individual Differences. 29, 6, 1057-1068.

Carroll, J.B, 1965. The prediction of success in foreign language training, in: Glaser (Ed.), Training , research, and education, New York: Wiley, pp.87-136.

Chan, A., Cheung, M., Sze, S., Leung, W., Cheung, R, 2008. Measuring vocabulary by free expression and recognition tasks: Implications for assessing children, adolescents, and young adults. Journal of Clinical and Experimental Neuropsychology, 30, 8, 892-902.

Chapelle, C. A., Heift, T, 2009. Individual learner differences in CALL: The field independence/dependence (FID) construct. Calico Journal. 26, 2, 246-266.

Chapelle, C. A., Jamieson J. 2008. Tips for teaching with CALL: Practical approaches to computerassisted language learning. White Plains, NY: Pearson-Longman.

Chapelle, C. A., Jamieson J. 1986. Computer-assisted language learning as a predictor of success in acquiring English as a Second Language. TESOL Quarterly, 20, 27-46.

Davidson, D, 2007. Study abroad and outcomes measurements: The case of Russian. Modern Language Journal. 91, 276-280.

De Raad, Boele \& Perugini, Marco (Eds.) 2002. Big five assessment. Ashland, OH, US: Hogrefe \& Huber Publishers.

Dewaele, J.-M, Fyrnham, A, 1999. Extraversion: the unloved variable in applied linguistic research. Language Learning. 49, 3, 509-544.

Ehrman, M, 2008. Personality and good language learners, in: Griffiths, C. Lessons from good language learners. Cambridge: Cambridge University Press, pp. 61-72. 
Graham, C. R, 2006. Hybrid learning systems: Definition, current trends, and future directions. In C. J. Bonk \& C. R. Graham (Eds.), Handbook of hybrid learning: Global perspectives, local designs. San Francisco, CA: Pfeiffer Publishing, pp. 3-21.

Graham, C. R., Allen, S., Ure, D, 2005. Benefits and challenges of hybrid learning environments, in: Khosrow-Pour, M. (Ed.), Encyclopedia of Information Science and Technology, I-V. Hershey, PA: Idea Group Inc., pp. 253-259.

Griffiths, R. 1991. Personality and second-language learning: Theory, research and practice, in: Sadtono, E, (Ed.) Language acquisition and the second/foreign language classroom, Singapore: SEAMEO Regional Language Center, pp. 103-155.

Heift, T. 2010. Developing an intelligent language tutor. CALICO Journal. 27, 3, 443-459.

Heift, T, 2001. Error-specific and individualized feedback in a web-based language tutoring system: Do they read it? ReCALL Journal. 13, 129-142.

Heift, T., Nicholson, D, 2001. Web delivery of adaptive and interactive language tutoring. International Journal of Artificial Intelligence in Education. 12, 310-325.

Hurtz, Gregory M.; Donovan, John J. (2000). Personality and job performance: The Big Five revisited. Journal of Applied Psychology, 85:6, 869-879

Irizarry, R, 2002. Self-efficacy and motivation effects on online psychology student retention. USDLA Journal. 16, 12, 55- 64 .

John, O. P., Srivastava, S. 1999. The Big-Five trait taxonomy: History, measurement, and theoretical perspectives, in: Pervin, L.A., \& John, O.P. (Eds.), Handbook of personality: Theory and research. New York, NY: Guilford Press, pp. 1-71.

John, O. P., Naumann, L. P., Soto, C. J, 2008. Paradigm Shift to the Integrative Big-Five Trait Taxonomy: History, Measurement, and Conceptual Issues, in: O. P. John, O.P., Robins, R.W., Pervin, L.A. (Eds.), Handbook of personality: Theory and research. New York, NY: Guilford Press, pp. 114158.

Little, D.G., 2004. Constructing a theory of learner autonomy: Some steps along the way. In K. Mäkinen, P. Kaikkonen \& V. Kohoen (Eds.), Future perspectives in foreign language education. Oulu: Oulu University Press, pp. 15-25

Lourde, G., Lomicka, L, 2008. Blended learning in teacher education: And investigation of classroom community across media. Contemporary issues in technology and teacher education. 8, 158-174.

Müller-Hartmann, A, 2005. Learning how to teach intercultural communicative competence via telecollaboration: a model for language teacher education, in: Internet-mediated Intercultural Foreign Language Education. Boston, MA: Thomson Heinle, pp. 63-84.

Murphy, L, 2008. Supporting learner autonomy: Developing practice through production of courses for distance learners of French, German and Spanish. Language Teaching Research. 12, 1, 83-102.

Myers, I.B., McCaulley, M.H., Quenk, N.L., Hammer, A.L, 1998. MBTI Manual: A Guide to the development and use of the Myers-Briggs type indicator, third edition ${ }^{\circledR}$. Palo Alto, CA: Consulting Psychological Press.

Osguthorpe, R. T., Graham, C. R, 2003. Hybrid learning systems: Definitions and 
directions. Quarterly Review of Distance Education. 4, 3, 227-234.

Paunonen, Sampo V.; Ashton, Michael C. (2001). Big Five factors and facets and the prediction of behavior. Journal of Personality and Social Psychology, 81:3, 524-539.

Reay, J, 2001. Hybrid learning—a fusion for the future. Knowledge Management

Review. 4, 3, 6 .

Roid, G. H, 2003. Stanford-Binet Intelligence Scales (5th ed.). Itasca, IL: Riverside.

Sasaki, M, 1996. Second language proficiency, foreign language aptitude, and intelligence: Quantitative and qualitative analyses. New York: P. Lang.

Schwienhorst, K, 2008. Learner Autonomy and CALL Environments. New York: Routledge.

Scida, E. E., Saury, R. E, 2006. Hybrid Courses and their impact on Student and Classroom Performance: A case study at the University of Virginia. Calico Journal. 23, 3, 517-531.

Senior, G., 2001. Shipley Institute of Living Scale. Retrieved on February 20, 2009 from http://www.usq.edu.au/users/senior/69301/Shipley.htm.

Sinclair, B, 1999. More than an act of faith? Evaluating learner autonomy in: Kennedy, C. (Ed.), Innovation and best practice in British ELT. London: Longman (in association with the British Council).

Skehan, P, 1991. Individual differences in second language learning, SSLA. 13, 275-298.

Skehan, P, 1989. Individual differences in second-language learning. London: Edward Arnold.

Smith, B., Álvarez-Torres, M.J., Zhao, Y, 2003. Features of CMC technologies and their impact on language learners' online interaction, Computers in Human Behavior. 19, 703-729.

Thorne, S, 2006. Pedagogical and praxiological lessons from Internet-mediated intercultural foreign language education research, in: Belz, J. \& Thorne, S. (Eds.), Internet-mediated intercultural foreign language education. Boston, MA: Thompson Heinle, pp. 2-30.

U.S. Department of Education (Office of Planning, Evaluation, and Policy Development), 2009.

Evaluation of evidence-based practices in online learning: A meta-analysis and review of online learning studies. Washington, D.C. Retrieved August 10, 2011 at

http://www.ed.gov/about/offices/list/opepd/ppss/reports.html.

Young, J. R, 2002. Hybrid' teaching seeks to end the divide between traditional and online instruction. Chronicle of Higher Education. 48, 28, A33-A34.

Wakamoto, N, 2009. Extroversion/introversion in foreign language learning: Interactions with learner strategy use. Bern: Peter Lang.

Wechsler, D, 2003. Wechsler Intelligence Scale for Children-Fourth Edition. San Antonio, TX: The Psychological Corporation.

Wechsler, D, 1997. Manual for the Wechsler Adult Intelligence Scale-Third Edition. San Antonio, TX: The Psychological Corporation. 
NOTICE: this is the author's version of a work that was accepted for publication in System. Changes resulting from the publishing process, such as peer review, editing, corrections, structural formatting, and other quality control mechanisms may not be reflected in this document. Changes may have been made to this work since it was submitted for publication. A definitive version was subsequently published in System, 40(4), 2012. DOI: 10.1016/j.system.2012.10.013

Zachary, R. A., Crumpton, E. and Spiegel, D. E. 1985, Estimating WAIS-R IQ from the Shipley Institute of Living Scale. J. Clin. Psychol., 41: 532-540.

Zachary, R. A., \& Western Psychological Services (Firm), 1991. Shipley Institute of Living Scale. Los Angeles, CA: WPS, Western Psychological Services. 
NOTICE: this is the author's version of a work that was accepted for publication in System. Changes resulting from the publishing process, such as peer review, editing, corrections, structural formatting, and other quality control mechanisms may not be reflected in this document. Changes may have been made to this work since it was submitted for publication. A definitive version was subsequently published in System, 40(4), 2012. DOI: $10.1016 /$ j.system.2012.10.013

\section{APPENDIX A}

Instructions: please take the time to fill out this survey. Thorough completion of all three sections will merit a total of 10 extra points towards your final grade.

\section{Part I}

Here are a number of characteristics that may or may not apply to you. For example, do you agree that this person is someone who likes to spend time with others? Please write a number next to each statement to indicate the extent to which you agree or disagree with that statement.

\begin{tabular}{|c|c|c|c|c|}
\hline $\begin{array}{c}\text { Disagree Strongly } \\
\qquad 1\end{array}$ & $\begin{array}{c}\text { Disagree a little } \\
2\end{array}$ & $\begin{array}{c}\text { Neither agree nor } \\
\text { disagree } \\
3\end{array}$ & $\begin{array}{c}\text { Agree a little } \\
4\end{array}$ & $\begin{array}{c}\text { Agree Strongly } \\
5\end{array}$ \\
\hline
\end{tabular}

\section{See Myself as Someone Who...}

\begin{tabular}{|c|c|}
\hline 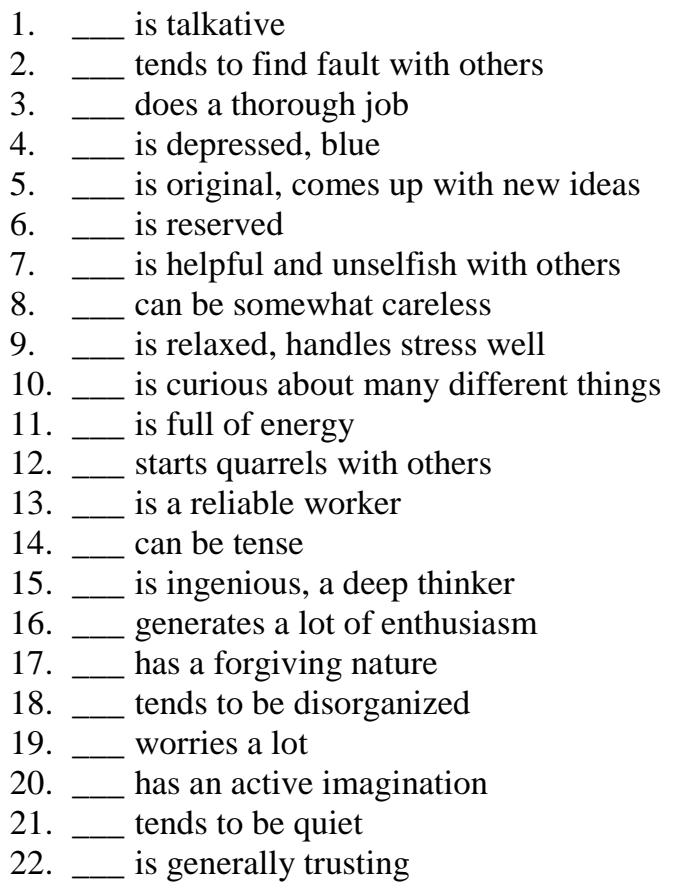 & 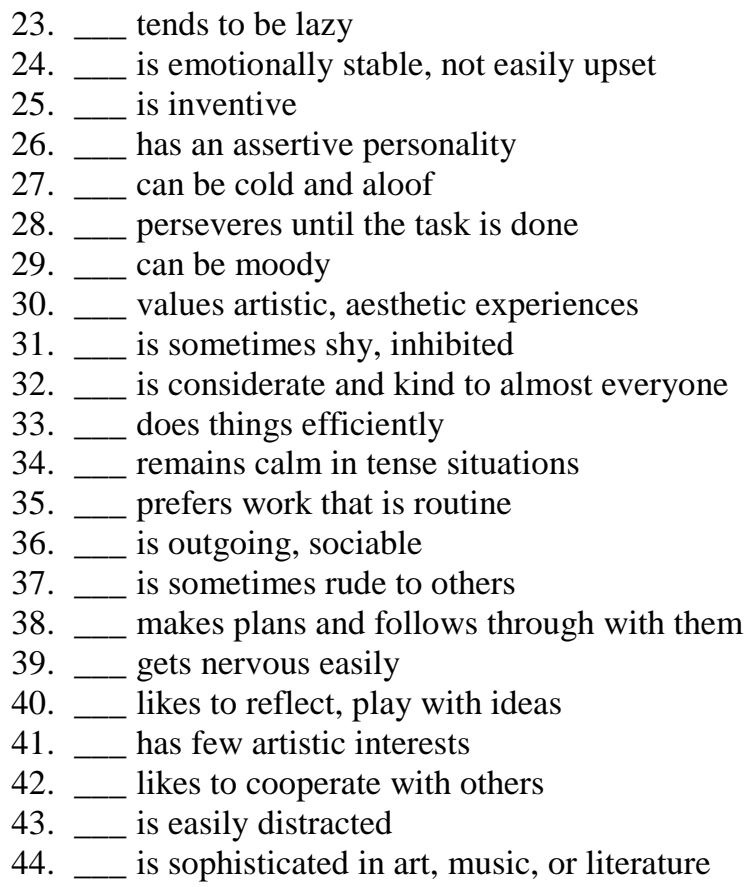 \\
\hline
\end{tabular}

\section{Part II}

On the test below, the first word in each line is printed in capital letters. Opposite are four other words. Circle the word that means the same thing or most nearly the same thing, as the first word. A sample has been worked out for you. If you don't know, then guess. ALL questions must be answered!

\section{Sample: WRITE}

1. TALK

2. PERMIT

3. PARDON

4. $\mathrm{COUCH}$

5. REMEMBER

6. TUMBLE

7. HIDEOUS

8. CORDIAL

$$
\text { work }
$$

draw

allow

forgive

pin

swim

drink

silvery

swift

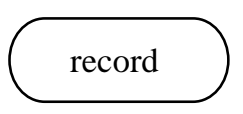

eat

sew

pound

eraser

recall

dress

tilted

muddy understand ponder

speak sleep

cut

drive

divide tell

sofa glass

number defy

fall think

young dreadful

leafy hearty 


\section{EVIDENT}

10. IMPOSTER

11. MERIT

12. FASCINATE

13. INDICATE

14. IGNORANT

15. FORTIFY

16. RENOWN

17. NARRATE

18. MASSIVE

19. HILARITY

20. SMIRCHED

21. SQUANDER

22. CAPTION

23. FACILITATE

24. JOCOSE

25. APPRISE

26. RUE

27. DENIZEN

28. DIVEST

29. AMULET

30. INEXORABLE

31. SERRATED

32. LISSOM

33. MOLLIFY

34. PLAGIARIZE

35. ORIFICE

36. QUERULOUS

37. PARIAH

38. ABET

39. TEMERITY

40. PRISTINE

\section{green}

conductor

deserve

welcome

defy

red

submerge

length

yield

bright

laughter

stolen

tease

drum

help

humorous

reduce

eat

senator

dispossess

charm

untidy

dried

moldy

mitigate

appropriate

brush

maniacal

outcast

waken

rashness

vain obvious

officer

distrust

fix

excite

sharp

strengthen

head

buy

large

speed

pointed

belittle

ballast

turn

paltry

strew

lament

inhabitant

intrude

orphan

involatile

notched

loose

direct

intend

hole

curious

priest

ensue

timidity

sound skeptical

book

fight

stir

signify

uninformed

vent

fame

associate

speedy

grace

remade

cut

heading

strip

fervid

inform

dominate

fish

rally

dingo

rigid

armed

supple

pertain

revoke

building

devout

lentil

incite

desire

first afraid

pretender

separate

enchant

bicker

precise

deaden

loyalty

tell

low

malice

soiled

waste

ape

bewilder

plain

delight

cure

atom

pledge

pond

sparse

blunt

convex

abuse

maintain

lute

complaining

locker

placate

kindness

level

In order to complete 41-60 follow these instructions:

Each dash (_ ) calls for either a number or a letter to be filled in. Every line is a separate item. Take the items in order, but don't spend too much time on any one.

41.12345 
42. white black short long down

43. $A B B C C D D$

44. $Z$ Y X W V U

45. 123212343234543456

46. NE/SW SE/NW E/W N/

47. Escape scape cape

48. oh ho rat tar mood

49. A Z B Y C X D

50. tot tot bard drab 537

51. mist is wasp as pint in tone

52. 57326732653265726573

53. knit in spud up both to stay

54. Scotland landscape scapegoat ee

55. surgeon 1234567 snore 17635 rogue

56. tam tan rib rid rat raw hip

57. tar pitch throw saloon bar rod fee tip end plank meal

58. $3124 \quad 82 \quad 73 \quad 154 \quad 46 \quad 13$

59. lag leg pen pin big bog rob

60. two $w$ four $r$ one o three

\section{Part III}

Please answer the following questions. Be specific and write legibly.

1. What aspects of the Tesoros online textbook were most beneficial to your success in this class?

2. Of the four learning skills (reading, writing, speaking, listening), which skill was MOST improved because of the online class? Please explain.

3. Over the course of the quarter, you had the opportunity to chat individually with the instructor and in a group online. Did you find chatting in groups beneficial? 
4. Do you think that the online chat was beneficial to your progress in oral communication in Spanish? Why or why not?

5. How did you find the feedback you received in the chat sessions (5 very helpful - 0 not helpful at all)

$$
\begin{array}{llllll}
5 & 4 & 3 & 2 & 1 & 0
\end{array}
$$

If helpful, please explain how it has been helpful for you

6. What part of the course did you find most helpful in your overall success as a student? $(1=$ least helpful, $2=$ helpful, $3=$ most helpful)

\section{TESOROS online textbook}

123 Online chat sessions with instructor

123 Class sessions twice a week

7. Would you recommend this course to anyone? Why or why not?

8. What year are you in school?

9. Previous classes in Spanish?

High school years:

Junior College semesters or quarters:

University level semesters or quarters:

10. How many online classes have you taken? 
Appendix B

\section{CHAT ACTIVITY}

I. Warm-up: greet one another in Spanish

II. ¿Una pizza deliciosa!

A. You and your partner arrange to get together one evening to make pizza and watch a movie. Figure out what evening and what movie will be best for the two of you.

B. Now you need to make a grocery list of the items you will need. You will write the ingredients in the wiki or chat box. Discuss the items out loud. Remember- you need to make the dough AND think of at least 4 toppings to put on your pizza. You can be creative as you like but you must both agree on what kind of pizza to make.

C. What store do you prefer to shop at? How much will each item cost? Go through and give an estimate for each item. At the end, you should have a grand total for how expensive it will be to make your pizza.

III. Role- play: take turns doing acting out the following situations

A. It's been a long quarter and you are talking to your friend about a few problems. Each of you state the following problems and receive advice from your partner. Make it a conversation.

-I can't stand my roommate

-My car got stolen and my parents are going to kill me

-I'm getting bad grades

-I saw my girl/boy friend going out with someone else 
NOTICE: this is the author's version of a work that was accepted for publication in System. Changes resulting from the publishing process, such as peer review, editing, corrections, structural formatting, and other quality control mechanisms may not be reflected in this document. Changes may have been made to this work since it was submitted for publication. A definitive version was subsequently published in System, 40(4), 2012.

DOI: 10.1016/j.system.2012.10.013

\section{B. Your friend is going to a formal dance.}

\section{Tell him}

1) What to wear, and what not to wear. The do's and don'ts of a date. (listen to her, pay for the food..)

Tell her

2) What to wear, what not to wear and the do's and don'ts as above.

\section{Despedirse (say goodbye to one another)}




\begin{tabular}{|l|l|l|}
\hline $\begin{array}{l}\text { Aptitude } \\
\text { Motivation } \\
\text { I.Q. } \\
\text { Personality } \\
\text { Age }\end{array}$ & $\rightarrow \quad \begin{array}{l}\text { Learner strategies } \\
\text { Learner styles }\end{array}$
\end{tabular}$\quad \rightarrow \begin{aligned} & \text { OUTCOME } \\
& * \text { Linguistic } \\
& \text { - proficiency } \\
& \text { - errors } \\
& * \text { Nonlinguistic } \\
& \text { - affective }\end{aligned}$

Figure 1: Influences on language learning (Skehan 1991: 227)

\section{First dimension: extraversion}

Implies an energetic approach toward the social and material world and includes traits such as sociability, activity, assertiveness, and positive emotionality.

\section{Second dimension: agreeableness}

Contrasts a prosocial and communal orientation towards others with antagonism and includes traits such as altruism tender-mindedness, trust, and modesty.

Highly correlated with preferences to work in groups.

Third dimension: conscientiousness

Describes socially prescribed impulse control that facilitates task- and goal-

directed behavior, such as thinking before acting, delaying gratification, following norms and rules, and planning.

Fourth dimension: neuroticism

Contrasts emotional stability and even-temperedness with negative emotionality, such as feeling anxious, nervous, sad and tense.

Fifth dimension: openness

Openness to experience that describes the breadth, depth, originality, and complexity of an individual's mental and experiential life. 


\section{First dimension: extraversion}

Implies an energetic approach toward the social and material world and includes

traits such as sociability, activity, assertiveness, and positive emotionality.

\section{Second dimension: agreeableness}

Contrasts a prosocial and communal orientation towards others with antagonism

and includes traits such as altruism tender-mindedness, trust, and modesty.

Highly correlated with preferences to work in groups.

Third dimension: conscientiousness

Describes socially prescribed impulse control that facilitates task- and goal-

directed behavior, such as thinking before acting, delaying gratification, following norms and rules, and planning.

Fourth dimension: neuroticism

Contrasts emotional stability and even-temperedness with negative emotionality, such as feeling anxious, nervous, sad and tense.

Fifth dimension: openness

Openness to experience that describes the breadth, depth, originality, and complexity of an individual's mental and experiential life. 


\section{Table 1}

Pearson correlations for social factors according to final grade

\begin{tabular}{ccc}
\hline Social factors & Final Grade & $\mathrm{p}$ \\
\hline Extraversion & .183 & .149 \\
Agreeableness & .055 & .668 \\
Conscientiousness & .381 & .002 \\
Neuroticism & -.022 & .862 \\
Openness & -.137 & .280 \\
\hline
\end{tabular}


Table 2

Spearman's Rho nonparametric correlations for cognitive factors according to learner preferences.

\begin{tabular}{ccccccc}
\hline & \multicolumn{2}{c}{$\begin{array}{c}\text { TESOROS online } \\
\text { materials }\end{array}$} & $\begin{array}{c}\text { Synchronous CMC } \\
\text { sessions }\end{array}$ & Class meetings \\
\hline Verbal intelligence & -.316 & $\mathrm{p}=.012^{*}$ & .014 & $\mathrm{p}=.916$ & -.002 & $\mathrm{p}=.987$ \\
Abstract intelligence & -.222 & $\mathrm{p}=.080$ & .028 & $\mathrm{p}=.829$ & .055 & $\mathrm{p}=.666$ \\
Shipley Score & -.321 & $\mathrm{p}=.010^{* *}$ & .036 & $\mathrm{p}=.777$ & .044 & $\mathrm{p}=.734$ \\
\hline
\end{tabular}


Table 3

Three learners along a continuum of low-high performance and BFI/Shipley scores

Participants Final BFI Shipley

performance Grade

Ext. Agr. Con. Neu. Op. Verbal Total

$\% \quad 5$ pt scale 40 pt. 80 pt.

\begin{tabular}{lllllllll}
\hline A: low & 67 & 3.75 & 3.0 & 3.11 & 2.88 & 3.9 & 24 & 56 \\
B: mid-high & 80 & 4.25 & 3.11 & 3.56 & 3.38 & 4.1 & 31 & 63 \\
C: high & 91 & 3.63 & 3.44 & 4.0 & 3.25 & 3.9 & 34 & 72 \\
\hline
\end{tabular}

